\title{
USO DE ADSORVENTES COMO ALTERNATIVA \\ NO TRATAMENTO DE \\ CONTAMINANTES ORGÂNICOS EM ÁGUAS E EFLUENTES LÍQUIDOS
}

Letícia de Jesus Castro Morais dos Santos - 1_lele@hotmail.com

Instituto Federal de Educação, Ciência e Tecnologia da Bahia

Gleide Nascimento Azevedo - gleide.azevedo@ hotmail.com

Instituto Federal de Educação, Ciência e Tecnologia da Bahia 


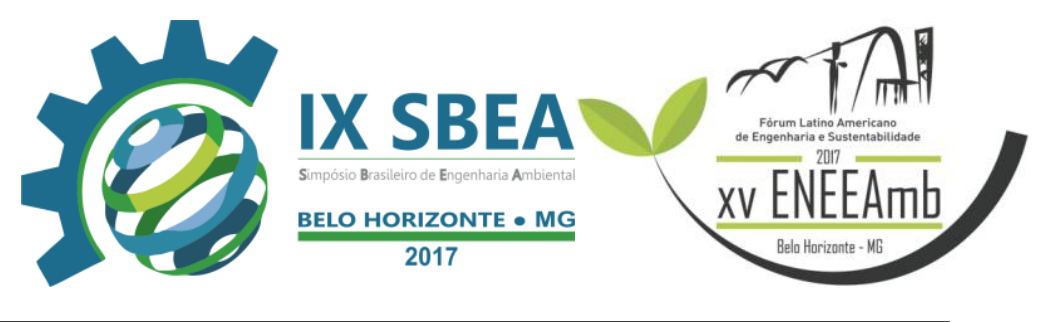

\section{RESUMO}

Atualmente toneladas de microcontaminantes orgânicos são lançados nos corpos hídricos através do esgoto sanitário, industriais e hospitalares, o mesmo possui uma carga química elevada quando não tratada corretamente, causando mudanças irreparáveis ao meio. Desta forma o presente artigo apresenta um estudo bibliográfico de variadas metodologias de adsorventes usados na adsorção de contaminantes orgânicos.

Palavras-chave: Contaminantes Orgânicos, Adsorventes, Metodologias.

\section{INTRODUÇÃO/OBJETIVO}

Os microcontaminantes orgânicos representam uma das classes de substâncias químicas lançadas diariamente no meio e se revelam como sério problema ambiental dos últimos tempos. Tais produtos quando lançados no meio interagem com as espécies resultando em impactos negativos à biota. A exemplo, tem-se os antibióticos, que ao serem lançados no meio, contribuem para a ocorrência e propagação de resistência microbiana (Kümmerer, 2003) e os estrógenos quanto aos riscos relacionados às funções endócrinas e reprodutivas em peixes selvagens, como, por exemplo, a feminização de peixes machos (Baronti et al., 2000).

Apesar dos microcontaminantes serem encontrados no meio em concentrações traços, na ordem de $\mathrm{ng} / \mathrm{L}$ e $\mu \mathrm{g} / \mathrm{L}$, estes compostos apresentam características e propriedades que os tornam recalcitrantes no meio aquático e terrestre. Uma vez no ambiente, os contaminantes orgânicos podem concentrar-se no solo através de atividades agropecuárias (MartínezCarballo et al., 2007) e de sumidouros. Podem sofrer lixiviação sendo transportados aos corpos hídricos superficiais e subterrâneos. Uma provável rota de contaminação hídrica advém do escoamento superficial de esgotos domésticos, hospitalares e industriais e da lixiviação sofrida pela disposição de lodo de esgoto no solo. Estudos demonstraram a ocorrência de contaminação de poluentes orgânicos persistentes em águas superficiais, subterrâneas, águas de abastecimento público ((Stackelberg et al., 2004 e 2007; Souza, 2008) , em esgoto tratado (Souza, 2011; Américo et al, 2012 )e em amostras de solo.

Os tratamentos convencionais de água e os tratamentos primário e secundário de esgoto não retiram, em sua totalidade, os contaminantes orgânicos presentes na água (Loffler et al., 2005 ; Souza, 2011; Américo et al, 2012). 


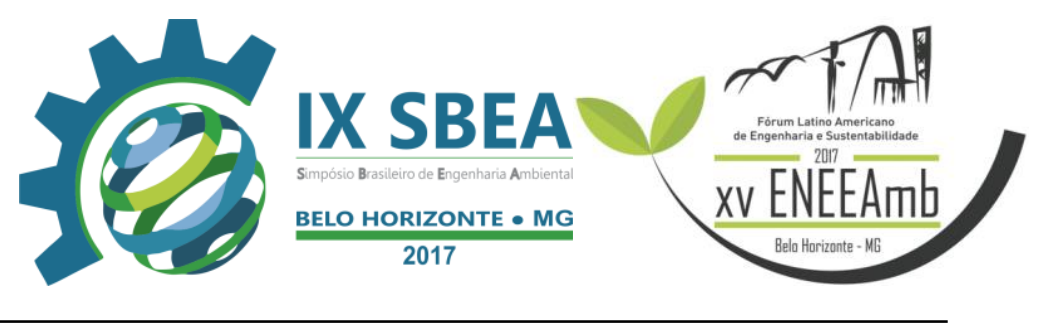

Novas tecnologias de tratamentos que objetivam a remoção desses poluentes têm sido bastante investigadas. Os principais métodos de tratamento de efluentes reportados na literatura envolvem processos físico/químicos e biológicos. Dentre eles, sobressaem os processos que objetivam a remoção dos fármacos em águas de estações de tratamento de esgoto e de água potável que são processos oxidativos avançados (POAs) (Vasconcelos, 2011; Ferreira, 2011), bioreatores com membranas (BRMs) e carvão ativado, ozonização (Krause, 2009), nanofiltração (Simões, 2010) e adsorventes naturais (Higarashi, 2012). Tais processos, com exceção do último são alternativas dispendiosas encarecendo os sistemas de tratamento de águas e de esgotos. Na tentativa de baratear os custos de tratamentos secundários de águas e efluentes, pesquisas com uso de adsorventes tem sido desenvolvidas em todo território nacional.

Neste sentido, o presente trabalho tem como objetivo apresentar uma revisão bibliográfica acerca dos principais adsorventes utilizados para a adsorção de contaminantes orgânicos em águas e efluentes líquidos.

\section{METODOLOGIA}

O presente artigo teve como processo metodológico um levantamento documental de artigos e teses em sites acadêmicos, seleção destes documentos e escolha daqueles que apresentaram variadas metodologias que podem ser empregadas no tratamento de adsorção dos contaminantes orgânicos em efluentes.

\section{RESULTADOS E DISCUSSÃO}

Dentre os métodos de tratamento de águas e efluentes líquidos, a bioadsorção tem-se mostrado como metodologia promissora (BILA \& DEZOTTI, 2007), economicamente exequível e ambientalmente correta, uma vez que há o aproveitamento de resíduos vegetais.

O processo da adsorção baseia-se em um fenômeno de separação de uma mistura implicando o contato de uma fase fluida (líquida) com uma fase rígida (adsorvente), onde moléculas, íons e átomos de uma determinada substância líquida ou gasosa são deslocados para uma superfície sólida, permanecendo aí retidos. Os solutos adsorvidos são estabelecidos como adsorvatos e o material sólido, ou seja, a fase rígida permanente é o adsorvente. A adsorção envolve interações eletrostáticas e as forças de Van der Waals entre o adsorvato e o adsorvente (fisiossorção) e quando há reação química (quimissorção) entre o sítio ativo de adsorção e o adsorvato (Di bernardo et al., 2002). 


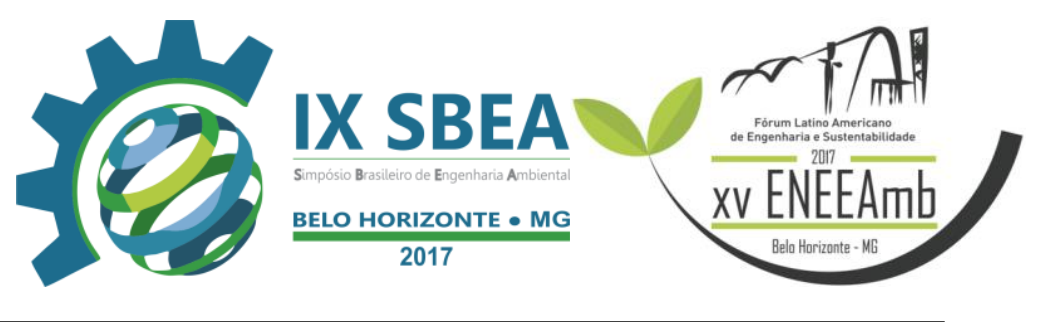

A adsorção é afetada pelas naturezas do adsorvente (matéria-prima utilizada na produção, grupos funcionais, área superficial, porosidade e processo de ativação) e do adsorvato (grupos funcionais, polaridade e peso molecular) bem como pelas condições físicas e químicas da solução e do processo (temperatura, $\mathrm{pH}$, agitação, concentração do adsorvato e tempo de contato) ( Haghseresht et al. ,2002). Recentemente, diferentes adsorventes têm sido estudados como uma alternativa na remoção de micropoluentes orgânicos presentes em efluentes líquidos. A tabela 1 mostra esses diferentes adsorventes utilizados atualmente para a remoção dos micropoluentes orgânicos de efluentes e águas.

Tabela 1: Adsorventes utilizados na remoção de micropoluentes orgânicos

\begin{tabular}{|c|c|c|c|}
\hline Adsorvente & Autor & Metodologia & Resultado \\
\hline Quitosana & $\begin{array}{c}\text { Cosmo et al } \\
\text { (2011) }\end{array}$ & $\begin{array}{l}\text { O autor utilizou a quitosana e o } \\
\text { carvão ativado para a remoção } \\
\text { do fármaco paracetamol para } \\
\text { saber qual possuía maior } \\
\text { potencial adsortivo. }\end{array}$ & $\begin{array}{l}\text { A quitosana apresentou } \\
128,67 \mu \mathrm{g} / \mathrm{g} \text {, sendo superior } \\
\text { ao carvão ativado com } 86,22 \\
\mu \mathrm{g} / \mathrm{g}\end{array}$ \\
\hline Turfa & $\begin{array}{l}\text { Fernandes } \\
\text { et al } \\
(2011)\end{array}$ & $\begin{array}{l}\text { Fernandes et al utilizou uma } \\
\text { amostra decomposta de turfa } \\
\text { para a remoção dos hormônios } \\
\text { 17b - ESTRADIOL E 17a - } \\
\text { ETINILESTRADIOL }\end{array}$ & $\begin{array}{llll}\text { Foi possível } & \text { atingirr } & \text { a } \\
\text { remoção de } & 76,2 \% & \text { do } \\
\text { hormônio } 17 b & \text { e } & 55,0 \% & \text { do } \\
\text { hormônio } 17 \mathrm{a} & & \end{array}$ \\
\hline Clarificação & $\begin{array}{l}\text { Lima } \\
(2013)\end{array}$ & $\begin{array}{l}\text { Lima usou o processo de } \\
\text { clarificação associado à } \\
\text { adsorção com carvão ativado e } \\
\text { coagulantes para remoção de } \\
\text { fármacos e desreguladores } \\
\text { endócrinos em águas naturais }\end{array}$ & $\begin{array}{l}\text { O autor constatou uma piora } \\
\text { na remoção dos micro- } \\
\text { poluentes, demonstrando } \\
\text { haver competição entre os } \\
\text { micro-contaminantes e as } \\
\text { espécies hidrolisadas do } \\
\text { coagulante pelos sítios } \\
\text { ativos do adsorvente. Porém, } \\
\text { uso do carvão ativado como } \\
\text { pré-tratamento aumentou a } \\
\text { eficiência de remoção de }\end{array}$ \\
\hline
\end{tabular}




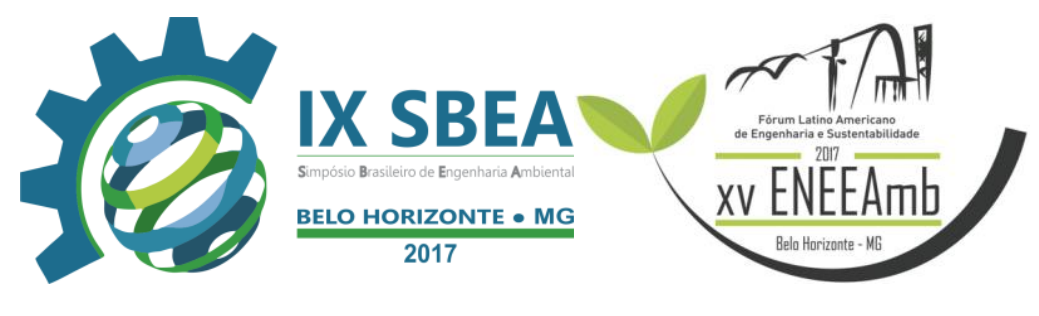

\begin{tabular}{|c|c|c|c|}
\hline & & & $\begin{array}{l}34 \% \mathrm{a} \quad 99,9 \% \quad \operatorname{dos} \\
\text { micropoluentes }\end{array}$ \\
\hline Zeólitas & $\begin{array}{c}\text { Fungaro \& } \\
\text { Bruno } \\
(2009)\end{array}$ & $\begin{array}{l}\text { Utilizou-se zeólitas sintetizadas } \\
\text { a partir das cinzas de carvão de } \\
\text { usina termoelétrica para } \\
\text { remoção do corante azul de } \\
\text { metileno em águas. }\end{array}$ & $\begin{array}{l}\text { A pesquisa atingiu um } \\
\text { percentual de } 90 \text { a } 92 \% \text { de } \\
\text { adsorção do corante }\end{array}$ \\
\hline $\begin{array}{c}\text { Carvão } \\
\text { Ativado em } \\
\text { pó - CAP }\end{array}$ & $\begin{array}{l}\text { Ferreira } \\
(2011)\end{array}$ & $\begin{array}{l}\text { Ferreira utilizou o CAP para } \\
\text { remoção de } 15 \text { micropoluentes } \\
\text { emergentes na ETE de Büsnau } \\
\text { na Alemanha }\end{array}$ & $\begin{array}{l}\text { Para dosagem de } 20 \mathrm{mg} / 1 \text { de } \\
\text { carvão ativado, houve } \\
\text { remoções superiores de } 90 \% \\
\text { dos fármacos e } 86 \% \text { a } 99 \% \\
\text { para as demais substâncias. }\end{array}$ \\
\hline $\begin{array}{c}\text { Lodo de } \\
\text { ETE têxteis }\end{array}$ & $\begin{array}{l}\text { Vasques } \\
\text { (2012) }\end{array}$ & $\begin{array}{l}\text { Vasques utilizou o lodo residual } \\
\text { obtido através de pirólise a } \\
\text { vácuo para remoção da cor e da } \\
\text { matéria orgânica do efluente } \\
\text { têxtil }\end{array}$ & $\begin{array}{l}\text { O autor obteve um resultado } \\
\text { de até } 99,5 \% \text { na remoção da } \\
\text { cor e matéria orgânica. }\end{array}$ \\
\hline $\begin{array}{c}\text { Casca de } \\
\text { Coco Verde } \\
\text { e Xisto }\end{array}$ & $\begin{array}{c}\text { Barbosa } \\
(2011)\end{array}$ & $\begin{array}{l}\text { Barbosa utilizou xisto retortado } \\
\text { e pó da casca do coco verde para } \\
\text { avaliar a eficiência na remoção } \\
\text { de arsênio (As), óleos e graxas } \\
(O \& G) \text { de um efluente }\end{array}$ & $\begin{array}{l}\text { Barbosa obteve uma } \\
\text { eficiência de quase } 100 \% \text { na } \\
\text { remoção ao arsênio e } 70 \% \\
\text { na remoção dos óleos e } \\
\text { graxas (O\&G) com o xisto. } \\
\text { Já com o pó da casca do } \\
\text { coco verde obteve } 80 \% \text { na } \\
\text { remoção dos óleos e graxas } \\
\text { (O\&G) e foi ineficiente na } \\
\text { remoção do arsênio. }\end{array}$ \\
\hline $\begin{array}{l}\text { Folhas de } \\
\text { Neem }\end{array}$ & $\begin{array}{l}\text { IMMICH } \\
\text { (2006) }\end{array}$ & $\begin{array}{l}\text { O autor utilizou as folhas de } \\
\text { Neem como adsorvente para } \\
\text { remoção de corantes em } \\
\text { efluentes têxteis e analisou a }\end{array}$ & $\begin{array}{l}\text { De acordo com os resultados } \\
\text { as folhas obtiveram uma } \\
\text { remoção do corante de azul } \\
\text { Maxilon GRL superior a }\end{array}$ \\
\hline
\end{tabular}




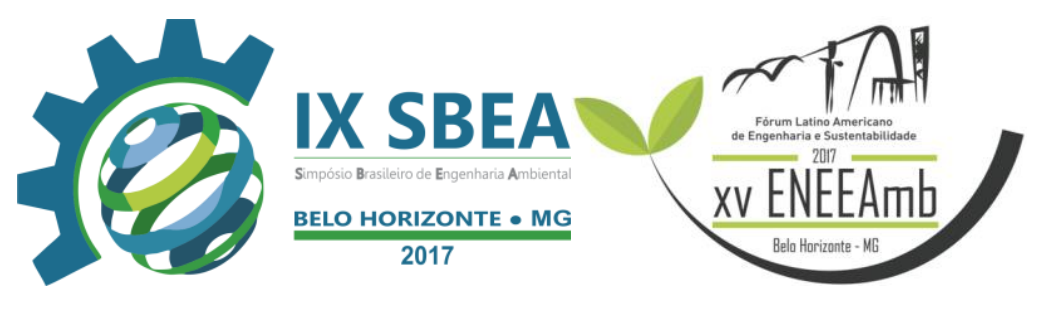

\begin{tabular}{|c|l|l|l|}
\hline & & $\begin{array}{l}\text { influência de alguns parâmetros } \\
\text { em diferentes classes de } \\
\text { corantes. }\end{array}$ & $\begin{array}{l}\text { 99\%, 97\% para o corante } \\
\text { Azul Lanaset 2R e 90\% para } \\
\text { Azul Remazol RR }\end{array}$ \\
\hline $\begin{array}{c}\text { Bagaço da } \\
\text { cana-de- } \\
\text { açúcar }\end{array}$ & $\begin{array}{c}\text { BRANDÃO } \\
\text { (2006) }\end{array}$ & $\begin{array}{l}\text { Brandão utilizou o bagaço da } \\
\text { cana para remoção de derivados } \\
\text { do petróleo }\end{array}$ & $\begin{array}{l}\text { O bagaço da cana-de-açúcar } \\
\text { foi capaz de adsorver 99\% } \\
\text { de gasolina e 90\% de n- } \\
\text { heptano presentes nas } \\
\text { amostras }\end{array}$ \\
\hline
\end{tabular}

Fonte: Autora, 2017.

\section{CONCLUSÕES/RECOMENDAÇÕES}

A utilização de adsorventes na remoção de micropoluentes apresenta como uma alternativa tecnológica ambientalmente sustentável ganhando interesse no meio acadêmico para o desenvolvimento tecnológico na remoção dos micropoluentes em águas.

Das pesquisas reportadas observou-se que o processo de adsorção foi nitidamente influenciado pela quantidade de adsorvato, da massa do adsorvente, do tempo de contato do soluto com o adsorvente, quantidade sítios ativos presentes no adsorvente, temperatura, tamanho da partícula do material adsorvente, dosagem do adsorvente, competição entre os micro-contaminantes e outras substâncias químicas hidrolisadas pelos sítios ativos do adsorvente.

Assim é necessária uma adaptação da metodologia escolhida para a realização do tratamento de adsorção dos micro-poluentes de acordo com a sua necessidade para o mesmo ter um grau de eficiência elevado. Dentre todos os adsorventes apresentados os que possuíram maior custo/beneficio foram àqueles utilizados através da biomassa como a casca do coco, bagaço da cana-de-açúcar e a folha de Neem pois o mesmo possui em grande quantidade no Brasil e é pouco utilizado auxiliando também na redução deste resíduo.

\section{REFERÊNCIAS BIBLIOGRÁFICAS}

AMÉRICO, J. H.; ISIQUE, W. D.; MINILLO, A.; CARVALHO, S. L. Fármacos em Uma Estação de Tratamento de Esgoto na Região Centro-Oeste do Brasil e os Riscos aos Recursos Hídricos. Revista Brasileira de Recursos Hídricos. Volume 17, n.3, p. 61-67- Jul/Set 2012. Disponível em: http://www.abrh.org.br/sgcv3/UserFiles/Sumarios/d8b3636f8df80e826675d 6b10f61272a_27322ace54d06ae91011e789da56cbb2.pdf. Acesso em: 19 maio de 2017. 


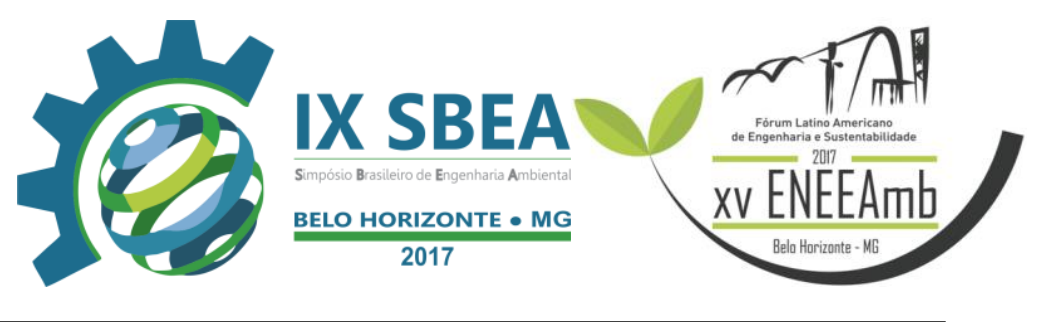

BARBOSA, A. L. S. Avaliação de um Sistema de Colunas de Leito Fixo Utilizando Xisto Retortado e Pó de casca do Coco para Remoção de Arsênio, Óleos e graxas de um efluente Real. Rio de Janeiro, 96 p, 2011. Dissertação (mestrado) - Universidade Federal do Rio de Janeiro. Disponível em: http://dissertacoes. poli.ufrj.br/dissertacoes/dissertpoli246.pdf. Acesso em: 12 maio 2017.

BARONTI, C; CURINI, R.; D’ascenzo, G.; Di Corcia, A.; Gentili, A.; Samperi, R. Monitoring Natural and Synthetic Estrogens at Activated Sludge Sewage Treatment Plants and in a Receiving River Water. Environmental Science and Technology, v.34, n. 24, p. 5059-5066, 2000.

BILA, D.M.; DEZOTTI, M. Desreguladores Endócrinos no Meio Ambiente: Efeitos e Consequências. Química Nova, vol. 30, n³, p.651-666. 2007. Disponível em: http://www.scielo.br/scielo.php?pid=s0100-40422007000300027\&script=sci_arttext. Acesso em: 16 maio 2017.

BELISÁRIO, M; BORGES, P. S.; GALAZZI, R. M.; PIERO, P. B. D.; ZORZAL, P. B.; RIBEIRO, A. V. F. N.; RIBEIRO, J. N. O emprego de Resíduos Naturais no Tratamento de Efluentes Contaminados com Fármacos Poluentes. Revista Inter Science Place, v. 2, n. 10, p. 6, 2009. Disponível em: http://interscienceplace.org/isp/index.php/isp/ article/viewFile/99/98. Acesso em: 23 maio 2017.

BRANDÃO, P. C. Avaliação do uso do bagaço-de-cana como adsorvente para a remoção de contaminantes, derivados do petróleo, de efluentes. Uberlândia, 2006. Dissertação

(Mestrado) - Universidade Federal de Uberlândia.

CERÁvOlO, R. A. Avaliação da Capacidade Adsortiva de Compostos Sulfurados do Óleo diesel em Carvão Ativado. Curitiba, 154 p., 2012. Dissertação (Mestrado) Universidade Federal do Paraná. Disponível em: http://dspace.c3sl.ufpr.br/dspace/bitstream/handle/1884/28855/R\%20\%20D\%20\%20RENAT A\%20DE\%20ABREU\%20CERAVOLO.pdf?sequence=1. Acesso em: 16 de maio 2017.

COSMO, P. C.; RIBEIRO, A. V. F. N.; RIBEIRO, J. N. Avaliação de Quitosana como Agente Removedor de Paracetamol em Águas de Abastecimento. In: VI Jornada de Iniciação científica. Vitória - Espírito Santo, 2011. Disponível em: 


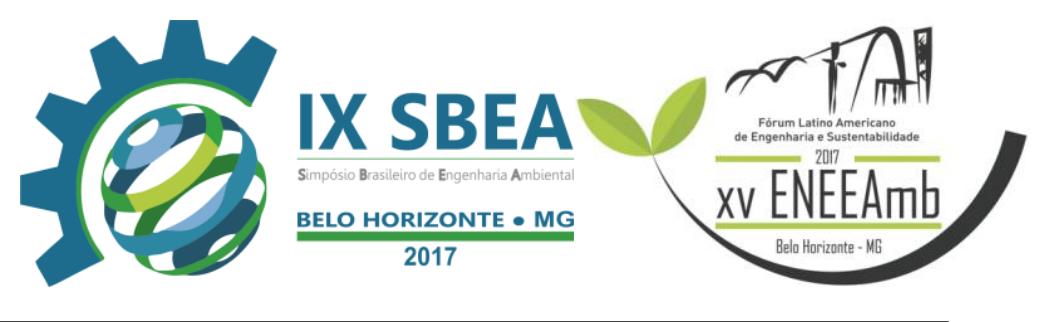

pse.ifes.edu.br/prppg/pesquisa/jornadas/.../045.../.\%5CT2364.pdf. Acesso em: 11 de maio 2017.

Dissertação (Mestrado) - Universidade Federal do Espírito Santo. Disponível em: http://www.ct.ufes.br/ppgea/files/DISSERTACAO_FERNANDA_DEPIZZOL_2006.pdf.

Acesso em: 11 maio 2017

DI BERNARDO, L; CENTURIONE FILHO, P. L. Ensaio de Tratabilidade de Água e dos Resíduos Gerados em Estações de Tratamento de Água. Rima. São Carlos, 237p., 2002.

FERNANDES, A. N.; GIOVANELA, M.; ALMEIDA, C. A. P. ; ESTEVES, V.I.; SIERRA, M. M. D; GRASSI, M. T. Remoção dos Hormônios 17b-estradiol e 17a-etinilestradiol de Soluções Aquosas Empregando a Turfa Decomposta Como Material Adsorvente. Química Nova, vol. 34, No. 9, p.1526-1533, 2011. Disponível em: http://www.lume.ufrgs.br/bitstream/handle/10183/72935/000822838.pdf?sequence=1.Acessa do. Acesso em: 19 de maio 2017.

FERREIRA, J. C. R. Remoção de Micropoluentes Emergentes em efluentes Sanitários através de Carão Ativado. Curitiba, 162 p., 2011. Dissertação (Mestrado) - Universidade Federal do Paraná. Disponível em: http://dspace.c3sl.ufpr.br:8080/dspace/bitstream/handle/1884/29741/R\%20-\%20D\%20\%20JULIANO\%20CESAR\%20REGO\%20FERREIRA.pdf?sequence=1.Acesso: 13 maio 2017.

FUNGARO, D. A. ; BRUNO, M.. Utilização de Zeólitas Sintetizadas a Partir de Cinza de Carvão para Remoção de Azul de Metileno em Água. ORBITAL.2009, p.4963.Disponível em: www.orbital.ufms.br/index.php/Chemistry/article/download/ 32/11. Acesso em: 12 maio 2017.

HAGHSERESHT, F.; NOURI, S.; FINNERTY, J. J.; LU, G. Q. Effects of surfaces chemistry on aromatic compound adsorption from dilute aqueous solutions by activated carbon. Journal of Physical Chemistry, v. 106, n. 42, p. 10935 - 10943, 2002. Disponível em: http://pubs.acs.org/doi/abs/10.1021/jp025522a. Acesso em: 16 maio 2017.

IMMICH, A. P. S. Remoção de Corantes de Efluentes Têxteis Utilizando Folhas de Azadirachta indica como Adsorvente. Florianópolis, 11 p., 2006. Dissertação (Mestrado) - 


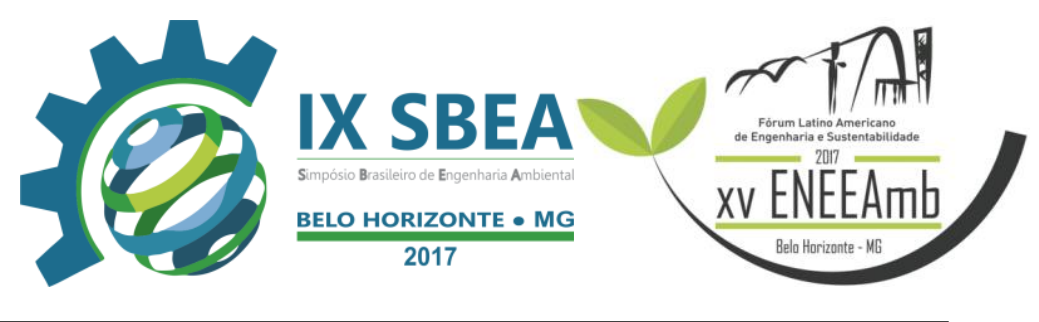

Universidade Federal de Santa Catarina. Disponível em: https://repositorio.ufsc.br/bitstream/handle/123456789/88917/233095.pdf?sequence=1. Acesso em: 23 maio 2017.

KRAUSE, L. G. T. Degradação do Antibiótico Sulfametoxazol por Ozonização e Avaliação da Atividade Antimicrobiana. Rio de Janeiro, 92 p., 2009. Dissertação (Doutorado) - Universidade Federal do Rio de Janeiro. Disponível em: http://fenix3.ufrj.br/60/teses/copped/LuizGustavoTavaresKrause.pdf. Acesso em: 13 maio 2017.

KÜMMERER, K. Significance of antibiotics in the environment. Journal of Antimicrobial Chemotherapy, v. 52, p. 5-7, 2003. Disponível em: http://jac.oxfordjournals.org/content/52/1/5.full.pdf. Acesso em: 13 maio 2017.

LIMA, D. R. S. .Remoção de Fármacos e Desreguladores Endócrinos de Águas Naturais por Clarificação Associada à Adsorção em Carvão Ativado em Pó. Ouro Preto, 126 p., 2013. Dissertação (Mestrado) - Universidade federal de Ouro Preto. Disponível: http://200.131.208.43/bitstream/123456789/3186/1/disserta\%c3\% 87\% c3\%83o_remo\%c3\%a7\%c3\%a3of\%c3\%a1rmacosdesreguladores.pdf. Acesso em: 11 maio 2017.

LOFFLER, D. et al. Environmental Fate of Pharmaceuticals in Water/ Sediment Systems. Environmental Science Technology, vol.39, p. 5209-5218, 2005. Disponível em: http://www.ncbi.nlm.nih.gov/pubmed/16082949. Acesso em: 15 maio 2017.

MARTÍNEZ, E.; BARREIRO, C.; SCHARF, S. \& Gans, O. Environmental monitoring study of selected veterinary antibiotics in animal manure and soils in Austria. Environmental Pollutants, n.148, p. 570-579, 2007. Disponível em: http://www.sciencedirect. com/science/article/pii/S0269749106006816. Acesso em: 18 maio 2017.

SIMÕES, P. M. S. V. Contribuição para o Estudo da Presença e Remoção de Compostos Emergentes de Filtros de UV em ETAR. Lisboa, 107 p., 2010. Dissertação (Mestrado) Universidade Nova de Lisboa. Disponível em: http://run.unl.pt/bitstream/10362/5129/1/Simoes_2010.pdf. Acesso em: 12 maio 2017.

SOUZA, J. B. G. Estudo da Ocorrência de Tetraciclinas e Estrógenos em Água Superficial, Subterrânea e Esgoto Tratado na Cidade de Campo Grande (MS). 


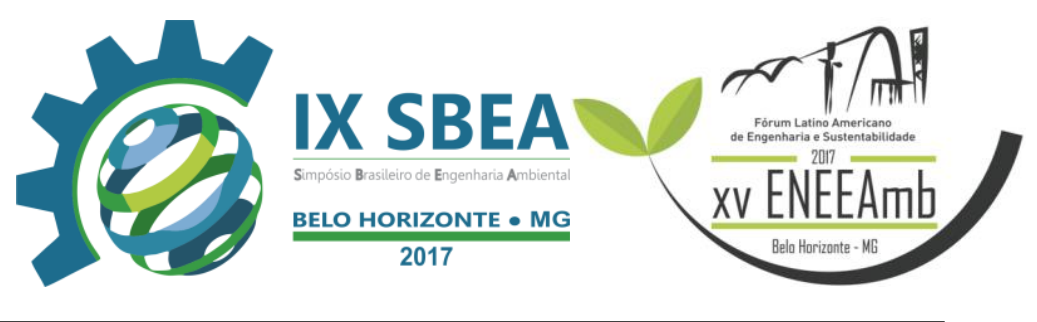

Araraquara, 160 p., 2008. Dissertação (Doutorado) - Universidade Estadual paulista. Disponível em: http://www.athena.biblioteca.unesp.br/exlibris/bd/biq/ 33004030072P8/ 2008/souza_jbg_dr_araiq.pdf. Acesso em: 20 maio 2017.

SOUZA, N. C. Avaliação de Micropoluentes Emergentes em Esgotos e Águas Superficiais. Fortaleza, 183 p., 2011. Dissesrtação (Doutorado) - Universidade Federal do Ceará. Disponível em: http://www.repositorio.ufc.br:8080/ri/bitstream/ 123456789 /2148/1/2011_tese_ncsouza.pdf. Acesso em: 06 maio 2017.

STACKELBERG, P. E.; FURLOG, E. D.; MEYER, M. T.; ZAUGG, S. D.; HENDERSON, A. K.; REISSMAN, D. B. Persistence of pharmaceutical compounds and other organic wastewater contaminants in a conventional drinking-water-treatment plant. Science of the Total Environment, v. 329, 2004.

STACKELBERG, P. E.; GIBS, J.; FURLONG, E. D.; MEYER, M. T.; ZAUGG, S. D.; Lippincott, R. L. Efficiency of conventional drinking-water-treatment process in removal of pharmaceuticals and other organic compounds. Science of the Total Environment, v. 377, 2007.

VASQUES, A. R.. Caracterização de Adsorventes obtidos por Combustão e Pirólise de Lodo residual e aplicação no Tratamento de Efluentes Têxteis de Florianópolis. Florianópolis, 130 p., 2012. Dissertação (Doutorado) - Universidade Federal de Santa Catarina. Disponível em: https://repositorio.ufsc.br/bitstream/handle/ 123456789/100696/313726.pdf?sequence=1. Acesso em: 05 maio 2017.

VASCONCELOS, O. M. S. R. Degradação do Antibiótico Amoxiclina em efluente de Indústria farmacêutica. Belo Horizonte, 136 p., 2011. Dissertação (Mestrado) Universidade Federal de Minas Gerais. Disponível em: http://www.bibliotecadigital.ufmg.br/dspace/bitstream/handle/1843/BUOS-8RKPSS/de grada_o_do_antibi_tico_amoxicilina_em_efluente_de_ind_stria_farmac_utica.pdf;jsessioni d=ABE195C64CA6A90C9672C66E191A6919?sequence=1. Acesso em: 05 maio 2017. 